
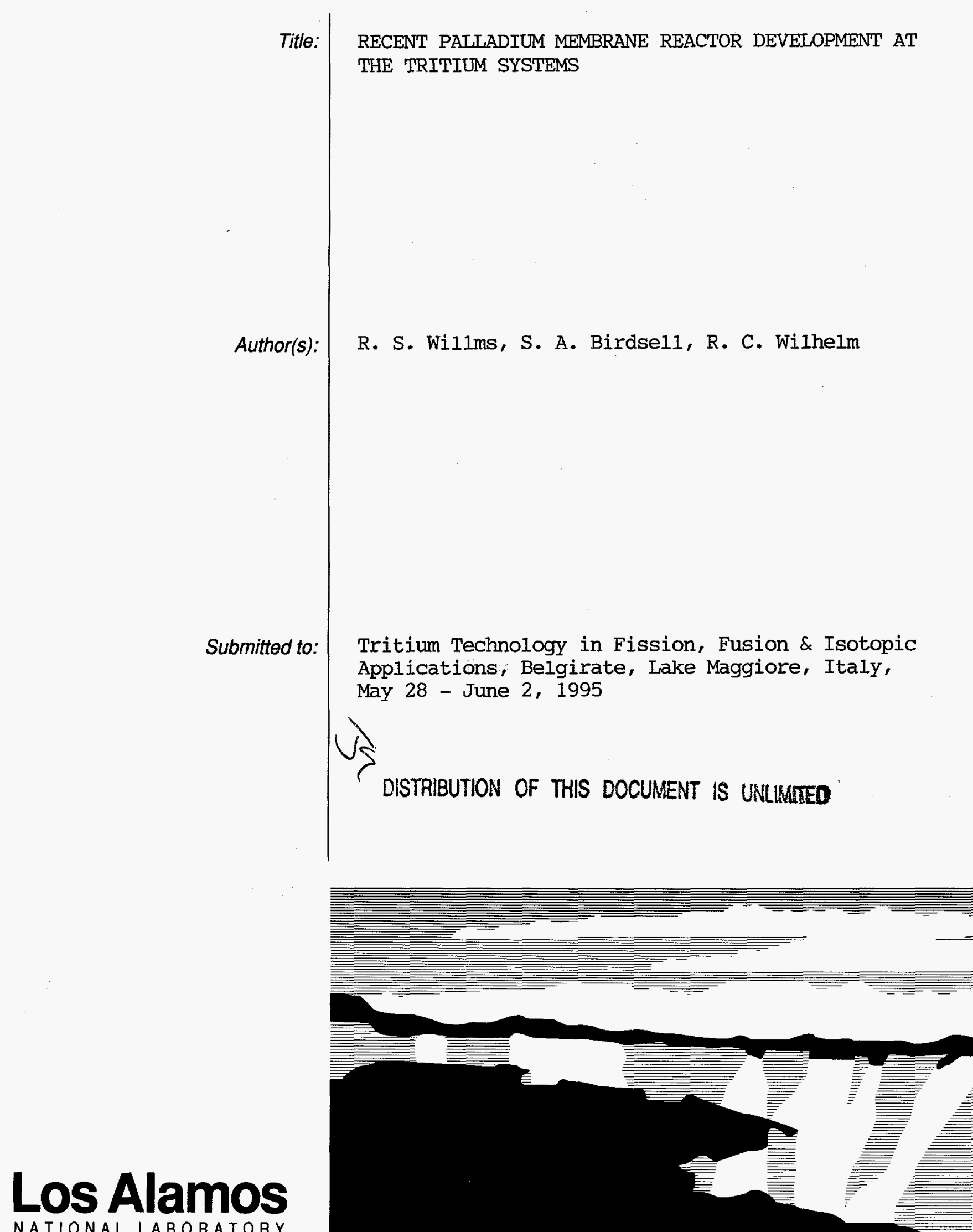

Los Alamos National Laboratory, an affirmative action/equal opportunity emplóyer, is operated by the University of California tor the U.S. Department of Energy under contract W-7405-ENG-36. By acceptance of this article, the publisher recognizes that the U.S. Government retains a nonexclusive, royalty-free license to publish or reproduce the published form of this contribution, or to allow others to do so, for U.S. Government purposes. The Los Alamos National Laboratory requests that the publisher identify this article as work performed under the auspices of the U.S. Department of 


\section{DISCLAIMER}

This report was prepared as an account of work sponsored by an agency of the United States Government. Neither the United States Government nor any agency thereof, nor any of their employees, make any warranty, express or implied, or assumes any legal liability or responsibility for the accuracy, completeness, or usefulness of any information, apparatus, product, or process disclosed, or represents that its use would not infringe privately owned rights. Reference herein to any specific commercial product, process, or service by trade name, trademark, manufacturer, or otherwise does not necessarily constitute or imply its endorsement, recommendation, or favoring by the United States Government or any agency thereof. The views and opinions of authors expressed herein do not necessarily state or reflect those of the United States Government or any agency thereof. 


\section{DISCLAIMER}

Portions of this document may be illegible in electronic image products. Images are produced from the best available original document. 


\title{
RECENT PALLADIUM MEMBRANE REACTOR DEVELOPMENT AT THE TRITIUM SYSTEMS TEST ASSEMBLY
}

\author{
R. Scott Willms, Stephen A. Birdsell and Richard C. Wilhelm \\ Mail Stop C-348 \\ Los Alamos National Laboratory \\ Los Alamos NM 87545 \\ 505-667-1710
}

\section{INTRODUCTION}

The palladium membrane reactor (PMR) is proving to be a simple and effective means for recovering hydrogen isotopes from fusion fuel impurities such as methane and water. This device directly combines two techniques which have long been utilized for hydrogen processing, namely catalytic shift reactions and palladium/silver permeators. Catalytic shift reactions such as water-gas shif, $\mathrm{H}_{2} \mathrm{O}+\mathrm{CO} \rightarrow \mathrm{H}_{2}+\mathrm{CO}_{2}$, and methane steam reforming, $\mathrm{CH}_{4}+\mathrm{H}_{2} \mathrm{O} \rightarrow 3 \mathrm{H}_{2}+\mathrm{CO}$, are used extensively in the petrochemical industry for producing free hydrogen from water and methane. Thermodynamic equilibrium limitations preclude the simple use of these reactions for the complete recovery of all hydrogen isotopes in a single processing pass. However, if free hydrogen liberated by these reactions is removed from the catalytic reactor, the equilibrium limitation is removed allowing for further free hydrogen generation. Palladium/silver membranes, which have long been used to generate ultra-pure hydrogen, provide a practical means for removing the liberated hydrogen. Such membranes have the fortuitous property of being exclusively permeable to hydrogen isotopes. By combining a catalytic reactor with a palladium/silver membrane, the PMR is capable of recovering essentially all of the hydrogen isotopes from fusion fuel impurities in a single processing pass. The device is relatively easy to construct and operate. It does not require the use of recycle streams or the addition of diluents. Indeed, the elegantly simple PMR is compact, inexpensive and reliable.

A proof-of-principle PMR has been constructed and tested at the Tritium Systems Test Assembly of Los Alamos National Laboratory. The first tests with this device showed that it was effective for the proposed purpose. These initial results and citations of pertinent literature were reported in [1]. This work concluded that a nickel catalyst was an appropriate choice for use in a PMR. More detailed testing of the PMR with such a catalyst was performed and reported in [2]. It was shown that a nickel catalyst-packed PMR did, indeed, recover hydrogen from water and methane with efficiencies approaching $100 \%$ in a single processing pass. These experiments were conducted over an extended period of time and no failure or need for regeneration was encountered.

These positive results have prompted further PMR development. Topics addressed include alternate PMR geometries and initial testing of the PMR with tritium. These are the subjects of this paper.

\section{EFFECT OF PMR ANNULAR DIAMETER}

A scale drawing of the original PMR is shown in figure 1 . The inner diameter of this PMR was 0.87 ". It was expected that the PMR annular diameter would effect performance. To quantify this effect a PMR shell with an inner diameter of $0.50^{\circ}$ was constructed and installed over the original palladium/silver tube assembly. The smaller diameter PMR was loaded with 0.125 " catalyst while the original PMR was operated with 0.25 " catalyst.

The smaller diameter PMR was operated with a watergas shift feed composition ratio of $\mathrm{CO}: \mathrm{H}_{2} \mathrm{O}=1.8: 1$ at 450 ${ }^{\circ} \mathrm{C}$. Total feed flowrates ranging between 30 and $110 \mathrm{sccm}$ were used. The hydrogen recovery results are plotted on figure 2 along side comparable data collected with the original PMR. Qualitatively, results are comparable. For both sets of data, at the lowest flowrates hydrogen recoveries approach $100 \%$, and, as the feed flowrate increases, a point is reached where recoveries fall progressively further below the $100 \%$ recovery line. However, the two datasets differ in that the 0.50" ID PMR reaches the point of departure from the $100 \%$ recovery line at about $60 \mathrm{sccm}$, while the 0.87 ' ID PMR reaches this point at about $120 \mathrm{sccm}$. 


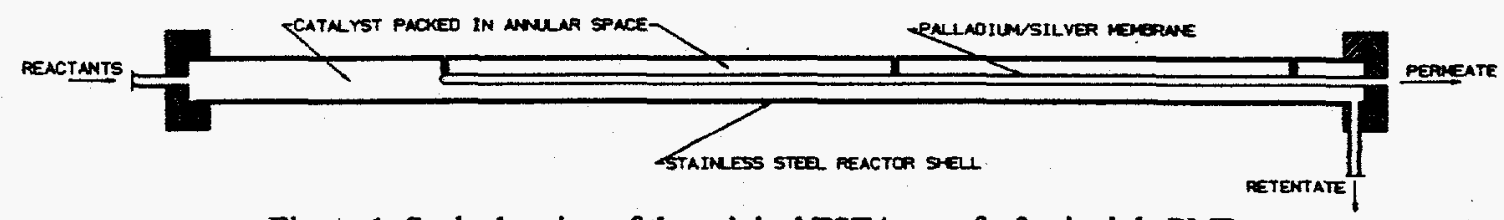

Figure 1 Scale drawing of the original TSTA proof-of-principle PMR

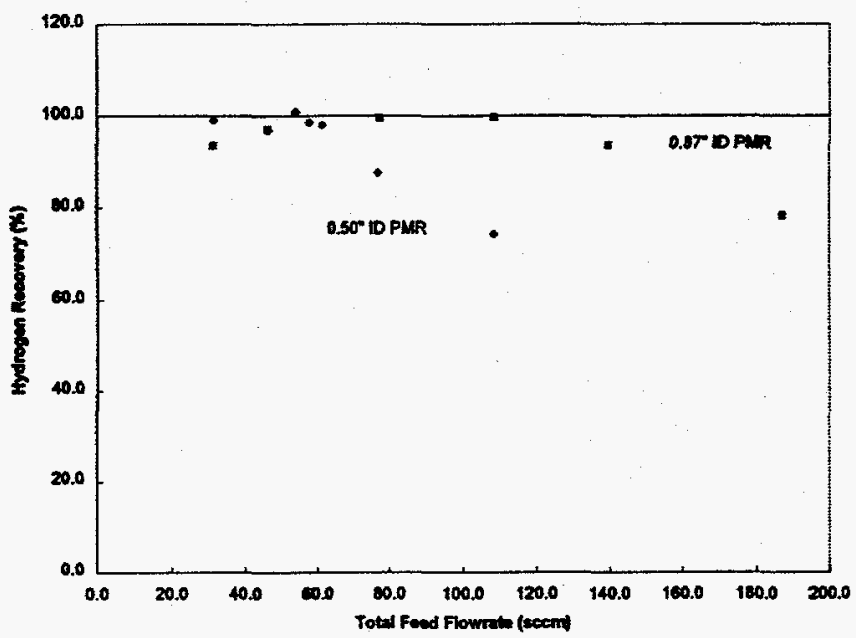

Figure 2 Comparison of hydrogen recoveries using different diameter PMR's

A primary design objective for the PMR is to process the highest possible flowrates without degraded hydrogen recovery performance. Within limits, this objective can be met by increasing the diameter of the PMR shell. This, by increasing the reactant residence time, provides the reactants with more time to react and the hydrogen with more time to permeate through the $\mathrm{Pd} / \mathrm{Ag}$ tube. This beneficial effect of increased residence time is the phenomenon observed on figure 2 . However, it must be recognized that, for a fixed length, as the PMR diameter continues to increase, there will eventually be reached a point at which significant amounts of free hydrogen isotopes will exist too far away from the $\mathrm{Pd} / \mathrm{Ag}$ tube to permeate. Rather they will travel near the PMR outer wall and reach the retentate outlet without permeating. There is no evidence of this "diffusion-limited" condition being reached in these experiments. Rather it is concluded that the PMR diameter could likely be further increased with only an accompanying improvement in PMR performance. Experiments designed to test this postulate are being planned.

\section{AN "INSIDE-OUT" PMR}

The PMR discussed above is referred to as an "outside-in" PMR since the hydrogen isotopes flow from the outside of the $\mathrm{Pd} / \mathrm{Ag}$ tube into its center. This geometry seems to be well suited for dealing with the bulk of the hydrogen isotopes that need to be recovered since it provides a large volume of catalyst. Loading the PMR with sufficient catalyst is important to 1) ensure adequate reaction kinetics for the relatively large quantities of reactants encountered and 2) provide plenty of catalyst to assimilate coke which may result from reactions such as methane cracking. However, the degree of hydrogen recovery for the PMR is limited by the vacuum which can be applied to the permeate side of the Pd/Ag membrane. The "outside-in" configuration requires that a vacuum be applied to the inside of a relatively small tube with limited conductance.

This limitation has prompted the consideration of an "inside-out" PMR. This configuration uses a Pd/Ag tube and stainless steel shell similar to the previous case, but the catalyst is packed inside the $\mathrm{Pd} / \mathrm{Ag}$ tube rather than in the annular space. Reactants are fed into the packed tube and hydrogen isotopes are recovered via permeation from within the Pd/Ag tube to the annular space. Due to the relatively large area of the annular space, there is a good conductance and high vacuum can be maintained on the permeate side. Since most of the hydrogen isotopes are expected to be removed by the "outside-in" PMR, there will be a rather small hydrogen isotope flux through the "inside-out" membrane so only a relatively small high vacuum pumping system will be required.

An example of an "inside-out" PMR is shown in figure 3. This device can be constructed by starting with a straight length of $\mathrm{Pd} / \mathrm{Ag}$ tube. This can be packed with catalyst then coiled on a mandrel.

An inside-out PMR was constructed using 0.125" $\mathrm{Pd} / \mathrm{Ag}$ tube. Initial testing showed that it worked well for recovering hydrogen isotopes from water and methane. However, due to a combination of factors including the small diameter $\mathrm{Pd} / \mathrm{Ag}$ tube and small catalyst pellets, excessive pressure drops were encountered on the retentate stream. Also it was found that the cartridge heater radiating heat from within the $\mathrm{Pd} / \mathrm{Ag}$ tube coil resulted in excessive temperature gradients when vacuum was applied to the shell. External heating which radiated heat inward from the shell walls was found to solve this problem. Learning from this experience, an "inside-out" PMR using larger diameter $\mathrm{Pd} / \mathrm{Ag}$ tube and larger catalyst pellets is currently being constructed and will soon be tested. 


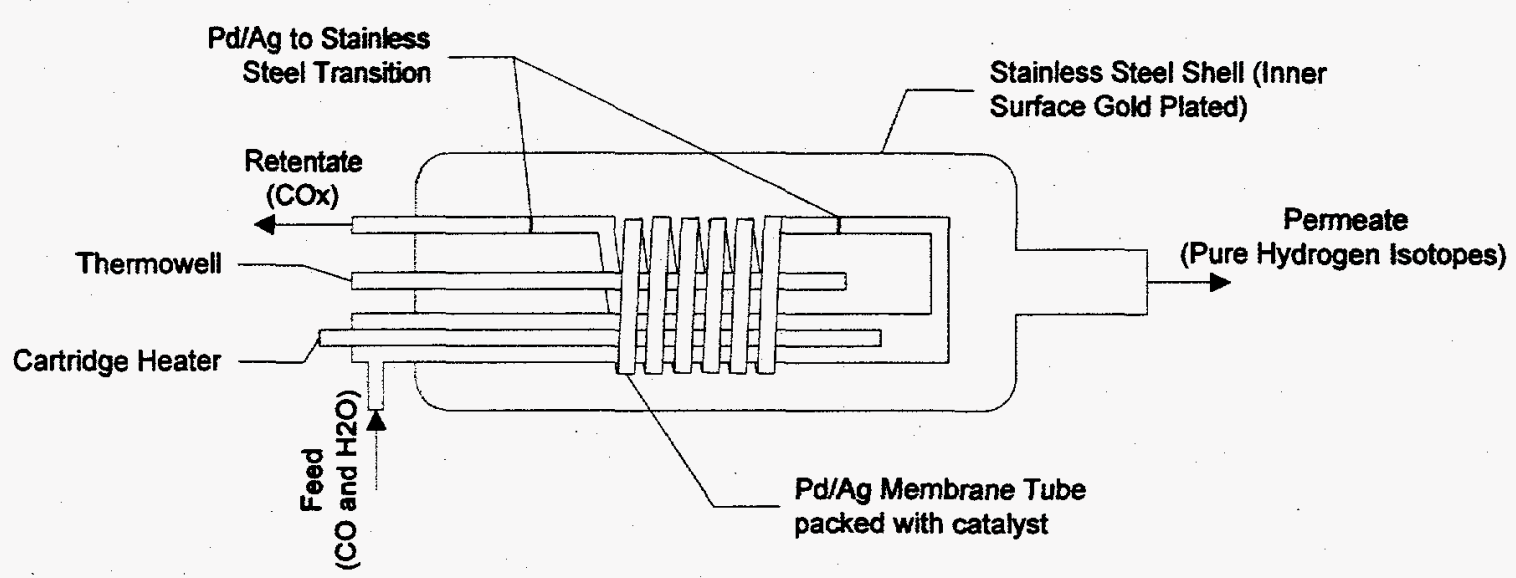

Figure 3 Prototype "Inside-Out" PMR

\section{FIRST PMR TEST WITH TRITIUM}

To further demonstrate the efficacy of the PMR for recovering hydrogen isotopes from fusion fuel impurities, an effort was mounted to test the original "outside-in" PMR (figure 1) with tritium. It was determined that it would be appropriate to test the PMR using a mixture of impurities which is being considered by the Tritium Plant team of the International Thermonuclear Experimental Reactor (ITER) Engineering Design Activity (EDA). As the first step in this undertaking it was necessary to construct a system to generate such a mixture of tritiated methane, tritiated water, $\mathrm{Q}_{2}$ (hydrogen isotopes) and helium.

For this purpose the system shown on figure 4 was built. The process begins by mixing normal protiated methane, tritium and $\mathrm{He}$. This mixture is passed over a $\mathrm{Ni}$ catalyst operated at $400^{\circ} \mathrm{C}$ to exchange protium in the methane with the free tritium. Experiments were conducted to ensure that the Ni catalyst bed, at actual operating conditions, did not crack methane. Oxygen is added to this equilibrated mixture before flowing into a $100-200^{\circ} \mathrm{C}$ Pt catalyst where the HT is oxidized to HTO. This component was also tested with protium to ensure that the HT was oxidized and that the methane was not oxidized. Proper design of the oxidation reactor was found to be necessary to avoid hot spots which could lead to methane oxidation. The end result of these processing steps is a mixture that closely approximates the concentrations specified by the ITER EDA Tritium Plant team for input to the impurities processing system. This mixture is fed directly to the PMR. If $100 \%$ efficient, the PMR will directly recover the HT from the water and methane, producing a stream of ultra-pure $\mathrm{HT}$ and a second stream of mostly tritium-free $\mathrm{He}$ and carbon oxides, as shown on figure 4 .

A process and instrumentation diagram for the first PMR test with tritium is shown by figure 5 . Standard compressed gas cylinders were used to supply all gases other than tritium which was supplied by a 50 liter product container. Vacuum was applied to the permeate side of the PMR via a Normetex 15 scroll pump backed by a metal bellows pump. The permeate was characterized by its pressure and flowrate and was returned either to a second 50 liter product container or to a 265 liter storage tank. Measurements for the PMR retentate included pressure, flowrate, humidity, gas chromatograph analysis and tritium content via an ionization chamber $\left(300 \mathrm{~cm}^{3}\right.$ right circular cylinder). The retentate was exhausted to the TSTA Tritium Waste Treatment (TWT) system.

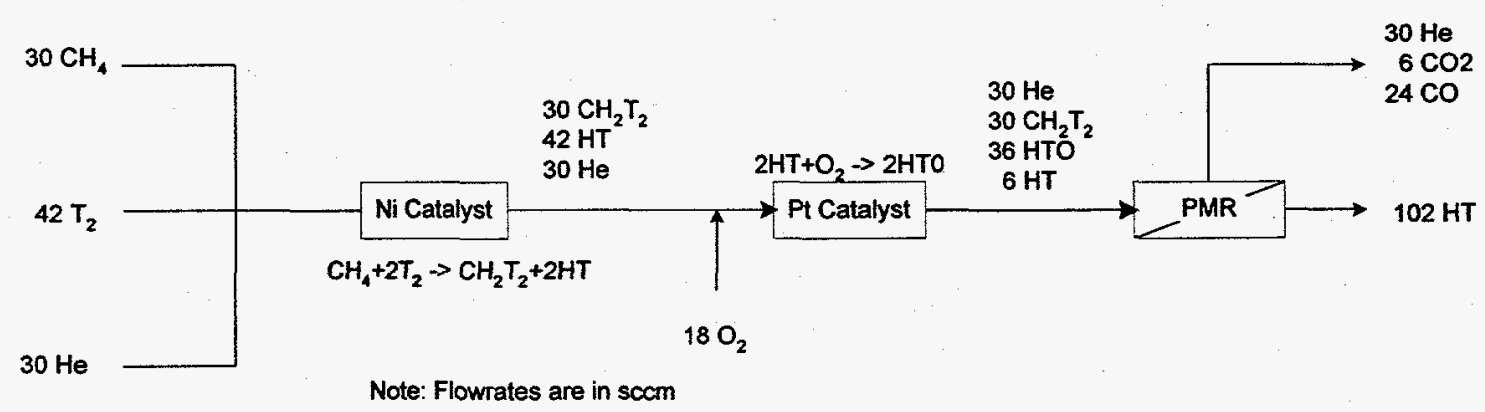

Figure 4 Processing Steps and Nominal Flowrates Used for the PMR First Test with Tritium 


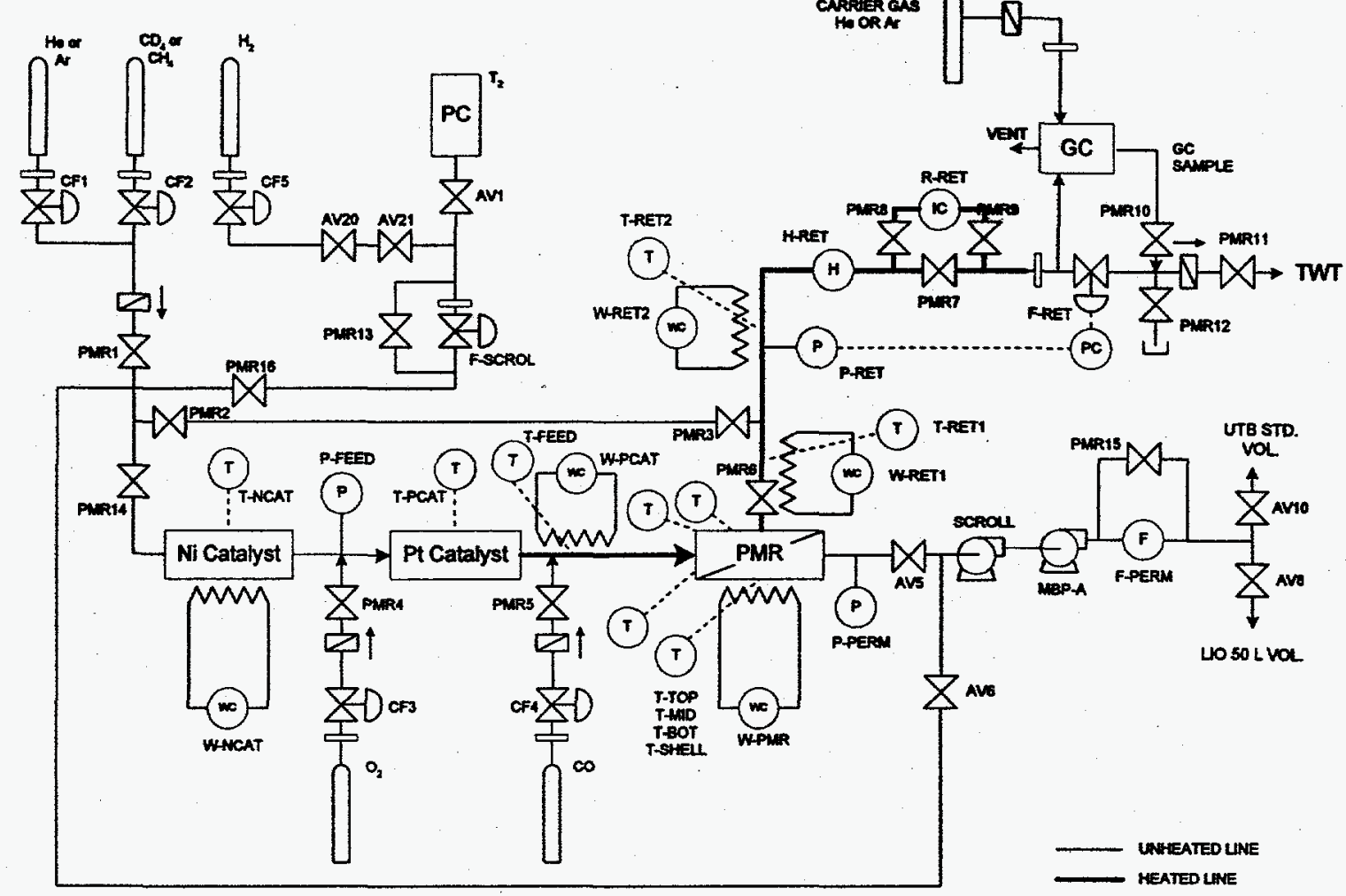

Figure 5 Process and Instrumentation Diagram for First PMR Test with Tritium

It was a venerable PMR which was used in this system. Indeed, this was the very first $0.87^{\prime \prime}$ inner diameter PMR which was constructed at TSTA and the one shown in figure 1. This same PMR had undergone over two years of intermittent testing with various catalysts including $\mathrm{Cu}, \mathrm{Fe}$ and $\mathrm{Ni}$-based materials. Operating conditions ranged from 310 to $600^{\circ} \mathrm{C}$ with the most extensive testing occurring at the middle to upper portion of this range. Throughout these campaigns, the $\mathrm{Pd} / \mathrm{Ag}$ membrane performance was consistent and no failure of any kind was encountered. This experience has built considerable confidence in the long-term reliability of the PMR.

For the tritium tests the PMR was packed with $134 \mathrm{~g}$ of a catalyst composed of about $70 \% \mathrm{Ni}$ on $\gamma$-alumina spineled with magnesium. The $\gamma$-alumina provides high surface area and the magnesium increases the catalyst stability at higher temperatures. The catalyst was obtained from the manufacturer in the reduced and stabilized form.

Non-tritium tests with the PMR had been conducted in a uniformly heated tube furnace. This, of course, was not practical for use in the glovebox which was required to house the tritium experiments. Thus, the PMR was retrofitted with insulated clamshell heaters. Unfortunately this did not provide the uniform heating of the PMR that was desired. It was observed that the thermocouple located near the PMR exit lines was typically $200^{\circ} \mathrm{C}$ cooler than the middle and feed thermocouples. This large difference appeared to be localized to the PMR exit. Nonetheless, the temperatures reported for the PMR tritium test must be considered as only approximate.

The first PMR test with tritium used a limited amount of tritium in the supply product container ("PC" on figure 5). Tritium was diluted with $\mathrm{H}_{2}$ so that the resulting mixture contained 5\% tritium. This was fed to the PMR test system along with the other gases shown under "Test 1 " in Table 1. The other measured test conditions and results are given in Table 1 as well. Test 2 was run somewhat hotter and with a greatly increased tritium concentration, i.e. $80 \%$ rather than $5 \%$. Test 3 used experimental conditions very similar to Test 2 , except that all feed flowrates were reduced. 
It must be noted that the radiation levels recorded in Table 1 are tentative values. The ionization chamber which was used to make these measurements received only a cursory calibration prior to this test. This calibration indicated that the chamber was reading a factor of 4.7 lower than theoretical calculations. This is a greater difference than would be expected. Among various explanations for this is a suspicion that the radiation levels being measured during the calibration were approaching the saturation level for the chamber. Nonetheless if the values shown in Table 1 are used to determine decontamination factors, i.e. tritium in the feed $\div$ tritium in the retentate, the values range between 150 and 400 .

Decontamination factors determined by $\mathrm{GC}$ and humidity readings are generally greater than those determined by ion chamber readings. This observation is consistent with the belief that the ion chamber calibration factor of 4.7 is too high.

It is clear that, qualitatively, the PMR was working quite well. Indeed, by any measure, well over $99 \%$ of the tritium was recovered in a single processing pass indicating that decontamination factors were good. Exactly how good they were, however, cannot be definitively stated from these data. Further tests are being planned with improved diagnostics, so better determinations are forthcoming.

\section{CONCLUSIONS}

Continued PMR development work is elucidating design improvements. This will guide the construction and testing of improved devices.

The first PMR test with tritium was a significant milestone. While the tritium results are preliminary, it was observed that the PMR worked well with tritium just as it had in extensive earlier non-tritium tests. The tritium tests showed that the bulk of tritium fed to the PMR was successfully recovered in ultrapure form in a relatively simple, "once-through" process. Essentially no waste (only carbon oxides and $\mathrm{He}$ ) was produced in the process. These tests have served to validate the belief that the PMR will become a valued technology for tritium processing systems.

Decontamination factors for the PMR are known to be limited by the quality of the permeate vacuum. For the "outside-in" PMR pressures below about 0.1 torr do not appear practical. However, an "inside-out" PMR is currently being considered. For this device much lower permeate pressures are practical and can be easily maintained with turbomolecular pumps. Thus, it appears judicious to process impurities with an "outside-in" PMR backed by a scroll pump, followed by an "inside-out"

Table 1 Conditions and Results for First PMR Test with Tritium

\begin{tabular}{|c|c|c|c|}
\hline Parameter & Test 1 & Test 2 & $\overline{\text { Test } 3}$ \\
\hline \multicolumn{4}{|l|}{ Input } \\
\hline$T$ conc. in $Q_{2}(\%)$ & 5 & 80 & 80 \\
\hline $\mathrm{T}_{\text {feed }}\left({ }^{\circ} \mathrm{C}\right)$ & 505 & 570 & 574 \\
\hline $\mathrm{T}_{\text {middle }}\left({ }^{\circ} \mathrm{C}\right)$ & 570 & 565 & 570 \\
\hline $\mathrm{T}_{\text {exit }}\left({ }^{\circ} \mathrm{C}\right)$ & 296 & 335 & 340 \\
\hline Inert Feed (sccm) & $20.4(\mathrm{Ar})$ & $20.6(\mathrm{Ar} \& \mathrm{He})$ & $\overline{15.6}$ \\
\hline $\mathrm{CH}_{4}$ Feed $(\mathrm{sccm})$ & 20.0 & 20.0 & $\overline{13.1}$ \\
\hline HTO Feed (sccm) & 25.2 & 25.2 & 17 \\
\hline HT Feed (sccm) & 5.2 & 20 & 8 \\
\hline Feed Pressure (torr) & 909 & 924 & 930 \\
\hline \multicolumn{4}{|l|}{ Output } \\
\hline Permeate Pressure (torr) & $\overline{0.4}$ & $\overline{0.6}$ & 0.5 \\
\hline Permeate Flowrate $(\mathrm{sccm})$ & 69.4 & 78 & 48 \\
\hline Ret. Humidity $\left({ }^{\circ} \mathrm{C}\right.$ dew point) & -6 & 6.9 & -24 \\
\hline Ret. Pressure (torr) & 902 & 901 & 902 \\
\hline Radiation $\left(\mathrm{Ci} / \mathrm{m}^{3}\right)$ & 1400 & 9300 & 12000 \\
\hline Radiation background $\left(\mathrm{Ci} / \mathrm{m}^{3}\right)$ & 470 & 2800 & 2600 \\
\hline Tritium Processed (g) & 0.09 & 2.4 & $\overline{2.4}$ \\
\hline
\end{tabular}


PMR backed by a turbomolecular pump. It is expected that such a system will realize very high, once-through decontamination factors. Experiments are being conducted and planned at TSTA to test such a system.

\section{REFERENCES}

[1] Willms, R. S., K. Okuno; "Recovery of Hydrogen from Impurities Using a Palladium Membrane Reactor"; Proceedings of the $15^{\text {th }}$ IEEE/NPSS

Symposium on Fusion Engineering, Hyannis, Mass., pp. 85-90, October 11-15, 1993.

[2] Willms, R. S., R. C. Wilhelm and S. Konishi; "Performance of a Palladium Membrane Reactor Using a Ni Catalyst for Fusion Fuel Impurities Processing", Proceedings of the $3^{\text {nd }}$ International Symposium on Fusion Nuclear Technology, Los Angeles, June 27-July 1, 1994. 